\title{
Community Service Learning among Health Sciences and Medical Undergraduates at a Malaysian setting: Providers' and Recipients' Portraits
}

\author{
Devinder Kaur Ajit Singh ${ }^{1 *}$ \\ Maziah Mamat ${ }^{1}$ \\ Roslee Rajikan ${ }^{2}$ \\ Nor Azlin Mohd Nordin ${ }^{1}$ \\ Cila Umat ${ }^{3}$ \\ Nor Najwatul Akmal Ab Rahman ${ }^{1}$ \\ Nor Ayuslinawati bt. Che Sidik ${ }^{1}$ \\ ${ }^{1}$ Physiotherapy Programme, School of Rehabilitation Sciences, Faculty of Health Sciences, \\ Universiti Kebangsaan Malaysia, Kuala Lumpur, Malaysia \\ ${ }^{2}$ Dietetics Program, School of Health Care Sciences, Faculty of Health Sciences, \\ Universiti Kebangsaan Malaysia, Kuala Lumpur, Malaysi \\ ${ }^{3}$ Audiology Programme, School of Rehabilitation Sciences, Faculty of Health Sciences, \\ Universiti Kebangsaan Malaysia, Kuala Lumpur, Malaysia \\ ${ }^{*}$ Corresponding Author
}

Doi: $10.1515 / \mathrm{mjss}-2017-0013$

\section{Abstract}

Community Service learning (CSL) or Community engagement integrated teaching and learning (CEITL) offers reciprocal learning to both the providers and recipients. While it is important to consider the opinions of both parties for successful CSL, limited information exists in this topic area locally. The objective of this study was to explore undergraduates' and communities' perceptions regarding their experience and services provided during CSL. Recollections of 12 health sciences and medical undergraduates, and 18 members of the community whom participated in CSL programmes were sought using focus group discussions. This included their understanding of the programme, its benefits, challenges and their solutions and preferred activities. Undergraduates perceived CSL as an activity considered important to provide interactions between students and community. The perceived benefits of CSL were enhancement of interpersonal communication skills, negotiation of mutual understanding and experiencing real life situations. Undergraduates suggested that CSL should be well planned and scheduled. The CSL was seen by the communities as a platform for the recipients' children to learn from the undergraduates as role models, future collaboration opportunities and health knowledge sharing. Weaknesses highlighted were; unstructured schedules, lack of variation in activities and CSL programme duration been too short to be effective. Suggestions provided for improved CSL were; extended time for health screening and better planned schedules. The findings suggest that undergraduates are aware of the significance of CSL in complementing their learning whereas the community have a positive outlook regarding CSL rendered by undergraduates. Further improvements are warranted in the implementation of more effective CSL programmes.

Keywords: Community Service learning, undergraduates, community 


\section{Introduction}

Community service learning is an experiential-based teaching aimed for reciprocal learning of both providers and recipients of the service (Furco, 2011). In our present setting it is referred to as Community engagement integrated teaching and learning CEITL). It requires the university and students to actively engage with the community through course-based service while linking the experience with previous knowledge and theory through a structured reflection practice. In CSL, there should be many opportunities to co-learn, co-create knowledge and co-evolve communitybased research theory and practice (Ochocka and Janzen, 2014). CSL requires commitment and resources in order to fulfill both learning objectives and community needs (Rosing et al. 2010). The American Association of Community Colleges (AACC) defines CSL as combining community service with academic instruction, focusing on critical, reflective thinking and personal and civic responsibility' (Prentice and Robinson 2010).

Learning through CSL has a positive implication on leadership skills (Goldstein et al. 2009), professionalism (Ferrari and Cather 2002), communication and social aptitudes among students (Leung et al. 2007). CSL also has the potential to change individuals' values and believes such as spiritual and moral values (Prentice and Robinson 2010). Besides cultural influences, regular CSL may nuture positive attitudes such as empathy and compassion towards the community (Jones and Hills 2001, Leung et al. 2012). Students are also reported to gain more knowledge and skills and are able to apply their theoretical knowledge through CSL (Prentice and Robinson 2010).

For health sciences and medical undergratuates, CSL provides a platform for community engagement and not merely a living lab to deliver health promotion, prevention and intervention services to the community. This experiential learning pedagogy is important in both health sciences and medical education because it connects class room theory to practical applications (Furco 2011) and provides opportunities for experience, practice and skills. On the other hand, the community as the recipients of this service can learn health related issues.

CSL has been structured to merge theory leant in classroom, volunteer work and real life experiences in the community (Brown \& Patricia 2007). It has been recommended that community engagements should be integrated into teaching and learning in higher education to generate sustainable and optimum benefits to all parties involved (O'Connor et al. 2011). A good universitycommunity engagement model should also incorporate addressing communities' criticism, complaints and needs. Community feedback is important for organizers or faculty to develop objectives and manage their future CSL programs. According to Ochocka and Janzen (2014), there are three guiding principles in performing community-based service learning: (i) community members as the main entity or the focus that they should gain voice and choice through the research process; (ii) university-community equal participation in designing the curriculum, implementation and dissemination of the outcome; (iii) positive social changes made by the community members as a result of the mutual partnership with the university service learning curriculum.

Many higher education institutions in Malaysia have ongoing research and knowledge driven community engaged services. Mostly, it is performed as a one off program and is delivered through volunteerism or as a social responsibility. In our settings, CSL is carried out widely as a one time program and is occasionally related to a course subject. However, taking CSL as part of the undergraduates' summative assessment of the course subject is still at a rudimentary stage. This practice does not contribute much to empowering the community and thus, being a successful platform for a service-learning environment. In an Asian study, it was reported that universitycommunity engagement programme failed to fulfill many of the CSL principles including community empowerment (Mastuti et al., 2014).

Moreover, Malaysia which consists of a multicultural society, different cultural backgrounds may influence people's perceptions about certain issues. It has been a concern that community level issues are rarely included when conducting studies about service-based pedagogy (Jones \& Hill, 2001). There is limited research exploring the perceptions of a Malay society regarding community service. The objective of this study was to explore undergraduates' (as the service providers) and the communities' (as the recipients) perceptions regarding their experience and 
service provided during CSL. This study was performed in view of evaluating the program and to assist in the planning of new improved academic CSL curriculum.

\section{Methods}

\subsection{Study design and participants}

Focus group discussions (FGD) were conducted among 12 first year medical and health sciences undergraduates from the Universiti Kebangsaan Malaysia, and 18 community members who participated in a three-day community service program at Mersing, Johor, Malaysia. Involvement of the all the villagers in this community was done through an invitation from the Faculty coordinator of this CSL program via the head of the village. This one time group community service project was to fulfill part of the objectives in a university based shared learning soft skill course for first year undergraduates.

The undergraduates were recruited randomly by the Faculty coordinator of this CSL program ensuring representation from both health sciences and medical faculties. The community members were invited to participate to include the head of the village and other villagers based on a voluntary basis. During this community service program, the first year undergraduates provided a two day health screening and education to the community that included organizing a session to get to know the undergraduates from the two faculties, opening ceremony of the program; blood pressure and blood sugar testing; poster exhibition and consultation sessions regarding hypertension, diabetes and healthy lifestyle. These undergraduates were also living in with the community as foster families during the three days of CSL program.

The inclusion criteria for the focus group participants were, full participation in this particular community service learning and able to communicate in Malay or English language. The study was approved by the Research and Ethics Committee of Universiti Kebangsaan Malaysia (NN-1112012). Informed written consent was obtained prior to the FGDs from all participants.

\subsection{Data collection}

The discussion with the community members were carried out twice immediately following the completion of the CSL programme. The undergraduates group met on three occasions in a week interval, two weeks following their participation in the programme. Prior to the discussion sessions with both the groups, a topic guide was developed based on the literature review and consensus, which included questions relating to understanding of CSL, perceived benefits of the programme, challenges faced and possible strategies to overcome challenges, and preferred CSL activities. The groups were moderated by a researcher who had experience in conducting focus group discussions. The moderator encouraged interactions among the participants and ensured that both groups fully discussed each study topic and that each participant had an adequate opportunity to express his or her views. All discussions lasted for 90 minutes and were audio taped. Field notes were taken and participant interaction maps were drawn at each of the group meetings. The key issues discussed during the first meeting session were fed back to participants at the beginning of the subsequent meetings to enable respondents' validation of the emerging ideas. A second meeting also served as a platform for further discussions on topics that were not fully addressed during the first meeting, to allow researchers in ensuring data saturation.

All data was analysed by two researchers using a thematic analysis approach. Audio tapes were first transcribed and the transcripts were reviewed for accuracy. Ideas were identified independently by the two researchers by constantly reading and re-reading the transcripts following which interpretations made by the researchers were compared and discussed until an agreement was reached. The two researchers also agreed on quotations from participants that best represented the ideas. An independent researcher validated the analysis findings. 


\section{Results}

\subsection{Participants' demographic characteristics}

Demographic data of the 30 participants is as shown in Tables 1 and 2.

\subsubsection{Participants' understanding of the CSL program}

Most of the undergraduates emphasized on the involvement of both the service providers (undergraduate participants, UP) and recipients (community participants, CP) when describing their understanding regarding CSL. Participants were aware that CSL can assist both providers of the service and recipients to learn from one another.

"Any program that gives benefit to society" (UP12)

"I think of community service as a curriculum, it is informal learning activity, not the one that we can learn in the class" (UP3)

"Beneficial for both the parties, the public knows health knowledge, students learnt living skills" (CP13)

CSL was seen as a platform to foster social networks and peer building; strengthen interactions between people and increase their understanding regarding lifestyle and cultural differences.

"We were in a society of a different place, gain more experience in terms of seeing more people " (UP8)

"Interacting with other faculty students, as we rarely see each other" (UP1)

"We rarely get to know of what was going on outside there. People have different culture everywhere" (UP9)

While connecting students with the community, undergraduates felt that community service is always needed, as an opportunity to change community's perception of them by directly interacting with the society.

"To show that the students nowadays are very outstanding, not just merely sitting in a building and attending classes. The community can see that they can learn from the university students"(UP7) "We're still connected with the society, students like us were actually kind of care about the world" (UP5)

There were participants who portrayed the CSL in activities that represented the identity of the program itself such as health screening and counseling activities.

"Community service is like a clinical, health examination" (UP7)

"First principle is foster families. The rest is cleaning activity; sports and gathering while get along with adopted family. It's a student's the field activity"(CP14)

\subsubsection{Benefits of CSL}

Improvement in communicational skills was one of the key benefits the undergraduate participants identified that could assist them in their future dealings as qualified professionals.

"Being able to communicate and identify issues and pay more respect for each other. Very useful as a pharmacist or doctor, the right meaning of communication with community, with patients "(UP10)

Exposure to teamwork, cooperation, social relationships and time management skills were the other benefits highlighted. 
"In terms of neighborhood; it is very strong. There is a very strong spirit. Others are the cooperation within the team. Time management is important too, I do need to be alert with time throughout the program" (UP9)

"A match during recreational event brings us together, building ties and unity of Malaysia" (CP15)

Undergraduate participants felt that they were seen as role models and motivators to the younger group in the community.

"We interact with the children there, they got to know that this service learning was as part of learning and we're not just attending some formal classes at the university. So, these children are getting more motivated to come into university to experience what we are going through" (UP7)

CSL rendered by undergraduates was also viewed as a podium to promote and enhance the reputation of the university.

"People should know what we exactly did, learn and have at the university. It has benefits to the community and the university" (UP12)

"There is a counter to explain a variety of educational registration, what they (UKM) got to offer us right there, its academics and courses" (CP5)

CSL was also perceived by both providers and recipients as an opportunity for the undergraduates to promote health and practice practical skills. Community members expressed that they felt comfortable to ask for more information and were empowered to take charge of their own wellbeing and their families' health.

"Learn how to use the tools, how are we going to handle the patients" (UP11)

"I personally learnt how to take the medical history from patients. When we meet the society, we can apply what we have learned "(UP2)

"If it's in our house we can freely ask. Get to know the detailed, never be shy, it's friendlier, easy to communicate. I sometimes felt more comfortable. When we have tendency to develop a disease, we should learn to take control of our self and our family"(CP13)

Through CSL, undergraduates were also able to reflect about the reality of their future undertakings. Community members felt that through CSL, the students can be exposed to real life situations.

"We should not always live in the comfort zone, must have a back-up plan. It's no guarantee to get a job straight away after graduation. Do not be too dependent"(UP1)

"Youngsters nowadays are less exposed to manual labor. So sometimes we give them exposure like that so that they can experience the village-like job. Like the correct way to cut the tree right way"(CP13)

\subsubsection{Challenges faced by undergraduates during delivering community service}

Poor publicity, organization and limited time to prepare and deliver services were seen as major challenges in delivering community service learning by the undergraduates.

"There was not much work that we could do. Students of Rahim Kajai College already cover for all things "(UP11)

"Just a week before the program; we were assigned to prepare the opening ceremony. It's stressful and we were running out of time. Don't make it last minute, should be made early "(UP12)

"The main thing is I don't think that they inform these people"(UP12)

"There is a slot for ice-breaking among students, this should have done before the program. Not creating a mess during the program as it was time consuming and this time could have been used for community service "(UP12)

"The lack of response from people here, I think that the information has not reached them" (CP13) 
Community members expressed that the services rendered were inadequate and they expected more than just routine examinations of blood sugar, blood pressure, cholesterol levels. They suggested examination and information for heart and knee conditions to be included, and printed materials or CDs to be provided for knowledge sharing.

"No check-up for heart. It was incomplete considering common diseases nowadays. No new learning. It's the same thing when we go see a doctor routinely"(CP17)

"Knee too. We move around a lot, it's painful. Why we get this pain, the causes and what to do"(CP14)

"I can share materials with others. But tell me simple things so I easily remember. It's better if they provided $C D$ or printed materials "(CP8)

Inadequate space to implement comprehensive CSL activities was also voiced out by the participants.

"The area is quite narrow for the closing ceremony" (UP2)

"There are a lot of counters, need to take long way to turn. Screening is quite ok. It's more comfortable if they can get a bigger place for this. Now, rather chaotic " (CP15)

Recipients of CSL were aware that the service was rendered by the first year undergraduates and due to that they were not expecting it to be of best standard.

"Probably it's their first time, maybe they felt nervous" (CP7)

"Not necessarily the final year, its fine with the first year as long as you can accept what you have learned and you know what you are doing "(CP15)

Community members expressed their disappointment that there was insufficient time for them to interact with the undergraduates in view of the foster families program.

"Always like this, they have been busy since first day" (CP15)

\subsubsection{Preferred activities during CSL}

Both groups preferred activities such as health talks, demonstrations and exhibitions focusing on related health issues. However, the community members requested for more specific information related to current health issues and knowledge in sub specialization disciplines.

"If it's going to dramatically improve health and community awareness, do the talks besides the exhibition" (UP3)

"Now we see a lot of dead babies from milk choking. Give a talk to mothers, mothers who have babies. If they brought expert in this area then it's good "(CP15)

\subsubsection{Solutions to overcome challenges faced during CSL}

For the undergraduates, they stressed more on improvements in terms of organization of the program. They requested for more time in planning activities in different community settings and a variation in the service provision. Extending the time of CSL programs and delivering the service in multiple ways were views given by community members.

"Next time better work and involve together in paperwork"(UP9)

"Not necessarily for foster family activities. Can go to the orphans, the homeless too "(UP3)

"Exhibition is nice but need more information" (UP9)

"The health screening recommended for morning until evening. You cannot come in the morning then come in the evening "(CP18)

"I think that three days just about to begin. A week might be better "(CP13)

"Change a bit the concept, related to current issues. In addition to talks do a little demo"(CP7) 


\section{Discussion}

In this focus group study, insights of both providers (medical and health sciences undergraduates) and recipients (community members) were sought regarding community service. The discussion focused on their understanding, benefits, expectations, challenges and suggestions for improvement of CSL. CSL in this study was organized under a soft skill training, project-based curriculum. It was considered unique in the sense that undergraduates from across faculties were involved and they were living with adopted families within a Malay community in village homes.

Most of the undergraduates viewed CSL as an involvement with the community and a direct approach for them to provide service. The community members agreed that this service was a common ground for an exchange of knowledge, and learning between the community members and undergraduate students. The community as the mature counterpart was aware of their participation in this service as a mutual learning podium. Awareness of participation in CSL is imperative for building mutual understanding, connections and engaged partnership between all parties (Birdsall 2005). Mutual understanding between both parties is important as it indicates an engaged partnership and diversity in learning executed through CSL.

Community should be regarded as knowledge-rich partners and university should not regard themselves as sole provider of academic domains. Community engagement co-creates knowledge to maximize or evolve knowledge and enrich the students teaching and learning experience (Small \& Uttal 2005). These are some of the key features in building healthy communities. Even though this agreement was partly achieved, it was evidenced that in the present CSL program, the community partners were not involved in the planning and design of the program. The undergraduates as service providers were still considered as the 'heroes' as illustrated by the statements requesting for heart and/or knee examinations as main health issues in the community when it was understood that service providers were first year undergraduates.

Undergraduates viewed CSL differently from the communities. The probable reason for the undergraduates not seeing from a similar lens may be due to the fact that it was not a particular discipline based CSL. Greater awareness of learning through CSL among undergraduates may be instilled by embedding CSL into a course curriculum. It has been suggested that strategic integration of CSL into a course curriculum can produce favorable outcomes (Berle 2006). However, there was a realization among the undergraduates that what they gained through this CSL may not have been possible in a classroom setting.

Undergraduates also noted that CSL carried out together with students across faculties provided them greater interaction opportunities. These findings are supported by a previous study confirming that CSL grant students the opportunities to expand and build their social network of peers (Prentice and Robinson 2010) and interactions with others (Drab et al. 2004). Interaction is believed to affect students' awareness of what they can contribute or offer to the community, besides learning about compassion, respect and other individuals' needs (Piper 2000).

The community members expressed that CSL provided circumstances for them to receive health knowledge while enhancing the understanding in living skills and cross cultural competency among undergraduates. Cultural competency and civic engagement has been reported to be improved via CSL in healthcare professionals (Nokes et al. 2005). Knowledge, attitude and skills are some of the attributes acquired in health professional cultural competency educational trainings but best teaching strategy is not known (Beach et al. 2005). Future research should investigate if optimal learning regarding cultural competencies could be developed via CSL.

CSL was viewed as a stand for building reputation as future graduates in societies by the undergraduates. Cooperation and networking between undergraduates and the community members was also highlighted in this study. This assisted the children in this community to learn from the students as role models. This was probably possible as the undergraduates were housed under the same roof with families from the community. To the best of the authors' knowledge, there are no such reports in earlier CSL related studies.

It can be concluded that both the undergraduates and community members groups perceived CSL as beneficial albeit still limited. Preferred activities such as health screening, education, demonstration and exhibitions were still 'professional-focus' rather than 'community-focus'. These 
views are in agreement with previous reports of CSL provided in other parts of the world (Prentice and Robinson 2010, Piper 2000). However, a few shortcomings highlighted by the participants were unstructured schedules due to limited preparation time, lack of variation in activities, limited space to implement activities and CSL programme duration been too short to be effective.

It is noteworthy that students involved in this CSL were all first year undergraduates who had limited theoretical knowledge to apply professional skills. This may be prominent when students are placed in more challenging situations such as community settings whereby more skills are required to connect to people from different lifestyles (Furco 2011, Prentice \& Robinson 2010). Previous CSL were reported to be carried out in nursing homes, homeless shelters or other settings for under privileged communities that are mostly homogenous (Prentice \& Robinson 2010, Piper 2000).

Suggestions provided for improved CSL by community members were extended time for health screening and better planned schedules. This information is vital for future planning of CSL and grooming future health care professionals. The importance of community members' contribution in CSL has been discussed by other authors in the field (Cruz and Giles 2000, Ochocka \& Janzen, 2014). The three guiding principles; community relevance, equal participation, action and change (Ochocka \& Janzen, 2014) should be taken into consideration in shaping future community-university engagement programs. As a result, meaningful collaborative partnership and positive social change in promoting social equity among communities may be possible through CSL (Ochocka \& Janzen, 2014). Approaching the local community, interacting with them, helping to increase their competency based on the community's strengths, readiness of each counterparts (university and community) to manage time and work both in program planning and implementation and to change the mindset of all the parties involved are some of the challenges highlighted in implementing CSL (Mastuti et al. 2014).

In summary, the community had a positive outlook regarding CSL rendered by health sciences and medical undergraduates. Health sciences and medical undergraduates also regarded CSL as an important learning event. This is in line with the main aim of CSL, whereby reciprocal learning occurs both with the providers and recipients (Furco 2011). Reciprocal learning during CSL has been reported in similar studies (Beck and Barnes 2007, Miron and Moely 2006). The integration of the activities of teaching, research and community service or engagement, undoubtedly takes considerable time and needs frequent reinforcement and is one of the challenges of CSL (Mastuti et al., 2014).

Limited opportunities for participants to express their views may have influenced the results of the study. In this study, FGDs were utilised to extract views from the participants. It has been suggested that 'kitchen table discussions (KTDs) is an innovative way to engage participants from rural communities (Hippe et al., 2014). As with the FGDs, KTDs involve an organised discussion with a selected group of people to gain information about their views and experiences of a topic in a less formal situation. KTDs are hosted by community members in their own homes and with participants who are known to each other such as family members, neighbours or close friends. It has been reported that KTDs help to break down some of the formalities of the FGDs and may help to capture community voices and the views of people less likely to participate in formal FGDs. KTDs might also be used in the future instead of FGDs to have better perspective from the communities who are less likely to participate in FGDs.

The other limitation in this study was that the community members were from the Malay race only. This may not be a representative of multiracial community in Malaysia. Future studies should explore the perceptions of a multiracial community regarding CSL. Further information may also be required among undergraduates from different years involved in longer and more structured CSL. Community involvement in planning and designing the curriculum and its implementation should be explored. A combined qualitative with quantitative study may assist in giving a clearer picture of the impact of CSL among undergraduates and communities.

\section{Conclusion}

In conclusion, the findings of this study suggest that undergraduates are aware of the significance 
of CSL in complementing their learning whereas the community have a positive outlook regarding CSL rendered by undergraduates. However, further improvements are warranted in the implementation of more effective CSL programmes. Thus, there is a definite need to incooperate more structured and comprehensive CSL curiculum health sciences and medical programmes to bring about an impact to both the undergraduates and community participants.

\section{Conflict of Interest}

The authors declare that there is no conflict of interest.

\section{Acknowledgements}

The authors would like to thank all the participants for their co-operation. This research was funded using a grants from Universiti Kebangsaan Malaysia (PTS-2012-087, PTS- 2013-137).

\section{References}

Beach, M. C., Price, E. G., Gary, T. L., Robinson, K. A., Gozu, A., Palacio, A., \& Powe, N. R. (2005). Cultural competency: A systematic review of health care provider educational interventions. Medical care, 43(4), 356.

Beck, A. J., \& Barnes, K. J. (2007). Reciprocal service-learning: Texas border Head Start and master of occupational therapy students. Occupational therapy in health care, 21(1-2), 7-23.

Berle, D. (2006). Incremental integration: A successful service-learning strategy. International Journal of Teaching and Learning in Higher Education, 18(1), 43-48.

Birdsall, J. T. (2005). Community voice: Community partners reflect on service learning. Journal for Civic Commitment, 5, 1-13.

Brown, P. L. (2007). Perceptions of individual experiences in a service learning course. Retrieved July 15, 2014, from http://scholar.lib.vt.edu/theses/available/etd-08022007-093023/unrestricted /Dissertation.pdf.

Cruz, N. I., \& Giles, D. E. (2000). Where's the community in service-learning research. Michigan Journal of Community Service Learning, 7(1), 28-34.

Drab, S., Lamsam, G., Connor, S., DeYoung, M., Steinmetz, K., \& Herbert, M. (2004). Incorporation of servicelearning across four years of the PharmD curriculum. American Journal of Pharmaceutical Education, 68(2), 44

Ferrari 3rd, N. D., \& Cather, G. A. (2001). Community service, learning and the medical student. Education for health (Abingdon, England), 15(2), 222-227.

Furco, A. (2011). Service-learning: A balanced approach to experiential education. International Journal for Global and Development Education Research 71-76.

Goldstein, A. O., Calleson, D., Bearman, R., Steiner, B. D., Frasier, P. Y., \& Slatt, L. (2009). Teaching advanced leadership skills in community service (ALSCS) to medical students. Academic medicine, 84(6), 754-764.

Hippe, J., Maddalena, V., Heath, S., Jesso, B., McCahon, M., \& Olson, K. (2014). Access to health services in Western Newfoundland, Canada: Issues, barriers and recommendations emerging from a communityengaged research project. Gateways: International Journal of Community Research and Engagement, 7(1), 67-84.

Jones, S. R., \& Hill, K. (2001). Crossing High Street: Understanding Diversity through Community ServiceLearning. Journal of College Student Development, 42(3), 204-16.

Leung, A. Y. M., Chan, S. S. C., Kwan, C. W., Cheung, M. K. T., Leung, S. S. K., \& Fong, D. Y. T. (2012). Service learning in medical and nursing training: a randomized controlled trial. Advances in health sciences education, 17(4), 529-545.

Leung, K. K., Liu, W. J., Wang, W. D., \& Chen, C. Y. (2007). Factors affecting students' evaluation in a community service-learning program. Advances in Health Sciences Education, 12(4), 475-490.

Mastuti, S., Masse, A., \& Tasruddin, R. (2014). University and community partnerships in South Sulawesi, Indonesia: Enhancing community capacity and promoting democratic governance. Gateways: International Journal of Community Research and Engagement, 7(1), 164-73.

Miron, D., \& Moely, B. E. (2006). Community agency voice and benefit in service-learning. Michigan Journal of Community Service Learning, 12(2).

O’Connor, K. M., McEwen, L., Owen, D., Lynch, K., \& Hill, S. (2011). Literature Review: Embedding Community Engagement in the Curriculum: An Example of University-Public Engagement. University of Gloucestershire, National Co-ordinating Center for Public Engagement. 
Ochocka, J., \& Janzen, R. (2014). Breathing Life into Theory: Illustrations of community based research: Hallmarks, functions and phases. Gateways: International Journal of Community Research and Engagement, 7, 18-33.

Piper, B., DeYoung, M., \& Lamsam, G. D. (2000). Student perceptions of a service-learning experience. American Journal of Pharmaceutical Education, 64(2), 159.

Prentice, M., \& Robinson, G. (2010). Improving Student Learning Outcomes with Service Learning. American Association of Community Colleges (NJ1).

Robin Keida MS, M. P. H., \& Susan Neville PhD, R. N. (2005). Does service-learning increase cultural competency, critical thinking, and civic engagement?. Journal of Nursing Education, 44(2), 65.

Rosing, H., Reed, S., Ferrari, J. R., \& Bothne, N. J. (2010). Understanding student complaints in the service learning pedagogy. American Journal of Community Psychology, 46(3-4), 472-481. 